\title{
Euthanasia in Minors: A Care-Ethics Perspective
}

\author{
Giulia Cuman* \\ Percorso Vita Onlus, Italy \\ *Corresponding author: Giulia Cuman, Community coordinator, Percorso Vita Onlus, Padova, Italy
}

Submission: 㭗September 20, 2017; Published: 眥 December 08, 2017

\section{Opinion}

The general involvement of minors in the decision-making that occurs within medical settings is not straight forward, and end-of-life decisions and euthanasia for minors pose peculiar ethical challenges for healthcare professionals [1]. Many of these challenges are a consequence of the complex interaction between healthcare professionals, parents, and patients [2]. Moreover, many consider the issue of euthanasia to be more controversial, because it deals with the ethical justification of permitting a capable minor to take part in the decision to use lethal drugs to terminate their life [3]. The ethical debates on end-of-life care in minors have taken place in many countries, in Europe, only the Netherlands and Belgium have adopted specific legislation that allows euthanasia in minors [4].

The amendment to the Belgian legislation sparked great debate, due to the peculiar decision to focus on the minor's capacity ("oordeelsbekwaamheid" in Dutch) [1]. The competency of minors has to be assessed case-by-case, with the involvement of physicians and psychiatrists or psychologists, who have great responsibility in determining competency (Section 3 §2.7, Belgian Act 2014 amendment). The Dutch law sets a minimum age of 12 years to request euthanasia, and if the minor is younger than16, parental approval is also required. Because the Dutch legislation provided this age limit, it was much less controversial than the Belgian Act, which raised difficult ethical questions about when and how to consider a minor as competent [1].

There is a need to understand better the ethical issues surrounding euthanasia in minors and whether these are different from those surrounding euthanasia in general [1]. It is important to adopt a care ethics approach in order to enrich the principle approach. The four principles of medical ethics are often addressed in the literature on euthanasia in minors, and the opponents of euthanasia in minors too often emphasize the slippery slope argument. However, as argued by Raus and van der Burg the slippery slope argument is weak, since it is impossible to prove empirically whether it is actually happening in the debate on euthanasia [5,6]. Moreover, it fails to take into consideration the evolutionary changes in perspectives and needs in society. It might be valuable to consider this argument, only to define appropriate regulation addressing possible degeneration of legalized practices, but this argument is mostly used in an emotional way, which might have great rhetorical power but it lacks of any rational justification [1]. This discourages a fruitful and critical discussion of more fundamental questions [6].

Minors are seen as a sensitive and vulnerable group, more prone to perceive pressure, and viewed as being incapable of giving autonomous, informed consent [1]. However, the capacity of discernment is unique and not related to chronological age. Thus is different from the legal capacity, which is merely arbitrary. Consequently, a case-by-case approach seems to be more coherent to determine the level of minors' involvement in the decisionmaking, and it is consistent with guidelines of prominent societies [7].

The approach based solely on the four principles of medical ethics simplifies the ethical decision-making process, but the result is to promote a rather superficial arguments. The principle approach focuses on a specific choice or action; thus generalizing the particular situation in order to identify and solve problems [8]. This suggests enriching the principle approach combining it with a care-ethics approach in the decision-making of euthanasia in minors [1]. This particular approach encourages the cultivation of an attentive attitude toward the patients' personal story and the nature of their relationships [8].

The care-ethics perspective says that every human being has to be viewed as being unique, an embodied person living within a particular relational network [9]. This relational network is a key attribute of the care-ethical approach in the context of euthanasia in minors: minors are embedded in a family structure in which they are dependent on their parents [1]. Children are generally recognized as part of a family unit rather than being independent individuals. This means that the parents' view, together with the child's own, should be acknowledged in order to achieve the child's best interest [7].

Within the care-ethical framework, the ethical problems are considered as embedded in a network of relationships. Hence, the best interest is not focused on the wishes of an isolated individual. 
In this context, the child's best interest is focused on the family network. In order to recognize the relational identity of the minor, we should listen to the stories told by the child, their family, physicians, and nurses. In fact, this will capture the complexity of the narrative context in which the child's care takes shape.

Within a care-ethics approach the connection with the vulnerable person and communication are seen as the key elements to develop in an interpretative dialogue. This connection serves the purpose to build and strengthen the relational web among all parties in order to increase both the level and the quality of the communication [1]. This is necessary to find the suitable answer to the care needs of a patient [8]. In order to reach the final goal of ethically sensitive care practices we must take into consideration the lived experiences of all people involved and promote an interpretative dialogue.

The final scope within a care-ethics perspective is to promote and enhance patients' dignity as much as possible, given their vulnerable status, as well to recognize the particular vulnerability of the parents and the care givers. When dealing with euthanasia in minors, the relational network is put under bigger pressure, and it is vital to find a solution that satisfies all parties. The careethics approach takes into consideration minors' concrete lived experiences in this context, and knowing the lived experience of the patient facilitates understanding and responding appropriately to their vulnerability in that particular circumstance [1]. The careethics approach demands great interpretative skills, because of its narrative and interpretative nature. Achieving this might help overcome some difficulties that regularly arise in the interpretation of the opinions of the people involved in these ethically sensitive end-of-life care practices [1].

\section{References}

1. Cuman G, Gastmans C (2017) Minors and euthanasia: a systematic review of argument-based ethics literature. Eur J Pediatric 176(7): 837847.

2. Pousset G, Bilsen J, Cohen J, Chambaere K, Deliens L, et al. (2010) Medical end of life decisions in children in Flanders, Belgium: a population-based post-mortem survey. Arch Pediatr Adolesc Med 164(6): 547-553.

3. Pousset G, Mortier F, Bilsen J, Cohen J, Deliens L (2011) Attitudes and practices of physicians regarding physician assisted dying in minors. Arch Dis Child 96(10): 948-953.

4. Schotsmans P, Meulenbergs T (2005) Euthanasia and palliative care in the low countries. Peeters, Leuven.

5. Raus K (2016) The extension of Belgium's euthanasia law to include competent minors. J Bioeth Inq 13(2): 305-315.

6. Van der Burg W (1991) The slippery slope argument. Ethics 102(1): 4265.

7. Jeremic V, Senecal K, Borry P, Chokoshvili D, Vears DF (2016) Participation of children in medical decision making: challenges and potential solutions. J Bioeth Inq 13(4): 525-534.

8. Gastmans C (2013) Dignity enhancing nursing care: a foundational ethical framework. Nurs Ethics 20(2): 142-149.

9. Groenhout RE (2004) Connected lives: human nature and an ethics of care, Rowman \& Little field Publishers, New York, USA, 21(4). 